\title{
Supervising the supervisors: What support do first-line supervisors need to be more effective in their supervisory role?
}

\author{
Frances Patterson, University of Stirling, Stirling, Scotland, UK
}

\begin{abstract}
INTRODUCTION: Stepping into a supervisory role in social work involves a shift of status, perspective and identity. New supervisors bring skills and experience which can be both asset and hindrance as they make the transition. Frequently they encounter gaps in training, support and supervision as well as dissonance between espoused policy and their own experience. This article identifies ways in which supervisors can be resourced to meet the challenge of their role and, as a result, be better placed to support others. It explores what is involved in supervising the supervisors, drawing on the experience of teaching managers on post-qualifying courses in professional supervision in Scotland.
\end{abstract}

APPROACH: Themes commonly applied to the supervision of practitioners are explored in relation to those who are one or more steps removed from direct practice; seeking to identify what has shared relevance and what may be distinctive to those in a supervisory role.

CONCLUSION: A congruent approach to support and supervision across all levels of an organisation helps foster a reflective culture which can engage with emotions and with complexity.

KEYWORDS: Supervision; reflection; containment; development

AOTEAROA NEW ZEALAND SOCIAL WORK 31(3), 46-57.

CORRESPONDENCE TO: Frances Patterson m.f.patterson@stir.ac.uk
Stepping into a supervisory role in social work involves a shift of status, perspective and identity. While there are undoubtedly transferable skills from direct practice, this is new territory which holds unfamiliar challenges. Lack of preparation or training is a common experience for new supervisors (Beddoe \& Davys, 2016; Mor Barak, Travis, \& Bess, 2004) and many find their way as best they can; influenced by their own supervision history; resolved to emulate what they appreciated most as a practitioner and avoid those behaviours or attitudes which they found unhelpful. Social work has been described as an "invisible trade" (Pithouse, 1987) made partly visible through discussions in supervision. Social work supervision itself is practised in spaces which are not open to view. The appropriate privacy and confidentiality of these conversations means that the interaction between supervisor and supervisee is rarely observed with the result that there are limited opportunities to learn from others or get direct feedback on one's own supervisory practice.

With a few exceptions (Beddoe \& Davys, 2016; Cousins, 2004; Patterson, 2015, 2017) there is sparse literature on the support and supervision of social work supervisors. This knowledge gap stands out when teaching on a supervision module where participants range from newly promoted first-line managers to those in senior management roles. For those supervising other managers, 
it is often necessary to translate theoretical perspectives to fit a context which is one, or more, steps removed from direct practice. While this has value in emphasising common ground, it risks oversight of what may be distinctive about supervising the supervisors. A more focused gaze on this area feels worthwhile, not least because of what is often missing in managers' own supervision and the tendency for managerial and administrative priorities to eclipse other dimensions (Ruch, 2008; Ward, 2012).

A discrepancy between the ideal and what actually happens is not uncommon in the context of supervision. Policy documents reflect aspirations for best practice but reality on the ground can diverge markedly due to a range of factors: policy ignorance, lack of commitment, and competing demands. Rankine, Beddoe, O'Brien, and Fouché (2018) carried out research in communitybased child welfare services exploring the tensions between managerial imperatives and relationship-based practice and highlighting the role of reflective supervision in supporting workers to develop their own theories-in-action. In similar vein, a study involving observation of supervision within children's services in a London borough demonstrated how managers frequently adopted a problem-solving approach in contrast to their stated intention of supporting workers' own reflection (Wilkins, Forrester, \& Grant, 2017).

For managers, the gap between policy rhetoric and their own supervision experience can be wide and such dissonance undermines an organisation's capacity to effectively contain the work undertaken. The concept of containment (Bion, 1962; Ruch, 2008; Smith, 2000) has relevance for social work supervision even in contexts where psychodynamic theory has little, if any, direct influence. Insights gained from Menzies-Lyth's (1970) seminal research on social defences against anxiety have been applied to diverse social care settings (Jones \& Wright, 2008; Lees, Myers, \& Rafferty, 2013; Whittaker, 2011) highlighting how failure to attend to the emotional impact of practice can lead to dysfunctional organisational processes; decline in staff motivation and have a detrimental impact on the quality of care provided. Ruch (2012) argues the case for reflective, relationship-based management and her model of holistic containment offers a counter-balance to the technical-rational cultures which currently prevail. Health and social care services intersect with people's lives when they need support; when they are in crisis; when they have experienced trauma. At its best, professional supervision provides a safe space where feelings stirred up by close and sustained involvement in this kind of work can be given expression so that practitioners retain the capacity to feel empathy; to see, to hear and to think clearly. Emotional work does not stop at first-line management level but pervades the whole fabric of the organisation. There appears, however, to be a lack of consistency in how the containing function is enacted across more senior tiers of management where, arguably, there is increasing complexity and no dilution of anxiety.

Informed by over 10 years' involvement in a teaching role with social services managers and supervisors in Scotland, this is a conceptual article reflecting on the support needs of first-line supervisors. It utilises well-established themes from supervision theory but examines these from the perspective of managers' own supervision, seeking to identify what may be lacking in, or distinctive to, their role. Developmental models are deliberately chosen to open this discussion in recognition of the significant personal and professional impact many experience as they transition from practitioner to manager roles. Included in this is the challenge of navigating power dynamics within supervisory relationships; having the confidence to exercise role authority when appropriate but able to value the expertise of others and appreciate supervision as a shared learning space (Carroll, 2009). The discussion then moves to the different functions of supervision and how these play out in relation to supervisors 
themselves. Influenced by Morrison's (1993) early observation that the unmet support needs of managers may contribute to their subsequent neglect of the support function when supervising others, there is particular focus on the restorative function and the purpose this serves for those not directly engaged in practice. This leads on to further exploration of the interplay between supervision and direct work: the role of supervisors in modelling relationship-based approaches and the ways in which emotions, anxiety in particular, infuse every level of an organisation involved in social care. Managers aware of the potency of below-thesurface dynamics appreciate the importance of reflective supervision where complex material can be processed. If they are to offer that "quiet space" (Beddoe, 2010, p. 1293) to their supervisees, this article argues that managers need regular protected time for reflecting on their own practice.

\section{Developmental models and transition from practice to the supervisory role}

Developmental models offer supervisors insight into the differing needs of practitioners with various levels of experience. Some caution is necessary as developmental progress is not a simple linear trajectory nor is there a fixed end point where the autonomous professional has no need of support or oversight. Those limitations notwithstanding, such models serve as a useful checking mechanism: a newly qualified worker seeking frequent guidance and reassurance feels appropriate while a more established practitioner displaying similar behaviour might prompt the supervisor to reflect on whether they have nurtured a degree of dependency or if some other factor has contributed to low confidence. Developmental frameworks are a way of charting the incremental steps of increasing confidence and competence expected as a worker's experience grows. This can be expressed as a fluctuating balance of dependence and autonomy (Hawkins \& Shohet, 2012) or as stages of conscious and unconscious competence (Strandgaard, 1981). Blanchard, Fowler, and Hawkins (2006) portray how the enthusiasm of a beginner wanes and disillusionment can set in when progress seems slow and hard-going. Consistent support is needed to motivate and encourage someone along the route towards capable performance and increasing self-reliance. These are well established models but, when combined with recognition of a developing supervisor's parallel journey, more complex pictures emerge.

For supervisors adapting to their new role, a staged process also applies (Davys \& Beddoe, 2010; Hawkins \& Smith, 2006; Hess, 1986). Initially, the need to provide answers, to be helpful and to do the right thing is a strong driver. If their former practitioner identity provides more secure grounding than the new managerial role, it is hardly surprising this is the expertise a supervisor will draw upon. Nor is this inappropriate so long as the supervisor's needs do not undermine a worker's capacity to find their own solutions or prevent them grappling with dilemmas which have no clear answer. In contrast to those who argue that key skills are transferable from social work practice into management roles (Coulshed \& Mullender, 2006; Tolleson Knee \& Folsom, 2012), Saltiel (2017, p.546) identifies the "limited usefulness" of managers' practice experience suggesting that different attributes are required to promote reflection and analysis on the part of their supervisees. Resisting the tendency to move too swiftly into problem-solving mode is shown to be difficult even for experienced managers who value reflective supervision (Wilkins et al. 2017), and it can be particularly challenging to acknowledge doubt and uncertainty when still trying to prove one's own worth as a supervisor. A felt need to offer solutions, while it may partly align with the developmental stage of a newly qualified worker, is likely to be a poor fit for more experienced practitioners and potentially leaves the supervisor feeling inadequate in their role. 
Becoming a supervisor involves role adjustment including acceptance of the power differential separating one from former peers (Cousins, 2004; Patterson, 2015). There is a transition from "doer role" to "leader role' (Stoner \& Stoner, 2013) which involves achieving things through others. While some new managers welcome this stepping back from direct practice, others may experience loss or reluctance to let go of the practitioner identity in which their skills and competence are well established. Such ambivalence can lead to an active-intrusive (Wonnacott, 2012) style of supervision; a micro-managing approach which limits the autonomy of workers. Until confidence has developed in the supervisory role there are potential hazards to be negotiated. Faced by staff members who are challenging or those who are highly experienced, it can be hard for novice supervisors to calibrate their approach avoiding both permissive and authoritarian extremes. The role strain inherent in managing the "tension between management control and professional autonomy" (Wong \& Lee, 2015, p. 165) is potentially acute for an inexperienced manager still struggling to find their feet.

Stoltenberg and Delworth (cited in Hawkins \& Smith, 2012) suggest that new managers gain a growing appreciation of complexity in their supervisory task but may be reticent to seek help from others. This resonates with research findings that managers' learning and development needs are given low priority both by themselves and by their organisations (Ofsted, 2012; Patterson \& George, 2014). It echoes the testimony of many first-line supervisors on post-qualifying courses who describe their experiences of infrequent or businessfocused supervision. While recognising a deficit, their attention is more focused on frontline practice than self-advocacy or seeing the organisation's supervision culture as a holistic entity. Later stages of the developmental model indicate supervisors' increasing commitment to critical reflection and their capacity to use different approaches in response to diverse situations and people. There is, however, no firm guarantee such progress will occur and Blair and Peake (1995, cited in Cousins, 2004) suggest that training makes an important contribution: "supervisors do not necessarily become more competent merely by gaining experience in providing supervision" (Cousins, 2004, p. 180).

Writing about the 'Support to Front Line Managers' Project' initiated by the Children's Workforce Development Council in England in 2010, Harlow (2016) describes employers' primary focus on training and education for new managers with less attention paid to other modes of learning such as coaching, mentoring or action learning. She highlights the value of "relational and reflective methods of preparing front line managers to undertake relational and reflective supervision with social work practitioners" (Harlow, 2016, p. 684). A comparable emphasis on "relationship-based practice supervision" is included in the Post-qualifying Standards for Social Work Practice Supervisors in Adult Social Care (Department of Health and Social Care, 2016, p. 9) and the newly developed Practice Supervisor Development Programme describes "the need for emotionally literate, reflective, curious supervision which promotes critical thinking, hopeful practice and wellbeing" (Holmes, 2018). These are encouraging signs that professional supervision is gaining status and recognition within the UK and resources being invested in supervisors' development. It remains clear, however, that stepping from a practitioner into a management role represents a significant transition. Most new supervisors are required to build relationships and manage the performance of workers with a diverse array of experience and commitment. There is a necessary adjustment to the delegated authority of a new role while having to earn authority from below (Obholzer, 1994) if they are to practise effectively. The challenge is heightened for those promoted within their own team or supervising in an integrated setting with staff from a range of professional backgrounds. 


\section{Functions of supervision and the place for support}

A triad of functions within professional supervision is commonly recognised (Hawkins \& Shohet, 2012; Inskipp \& Proctor, 1988; Kadushin, 1976). To the three core elements of management, development and support, Morrison (2005) adds mediation as a fourth function, taking account of the supervisor's pivotal role in communicating both upwards and downwards in an organisation. The language used to describe the functions varies across supervision literature, in part reflecting professional cultures but also adapting to changing expectations, for example, Hawkins and Shohet $(2006,2012)$ intentionally use developmental, resourcing and qualitative functions to emphasise shared responsibility between supervisor and supervisee. Writing in a health context, Wallbank (2010) has chosen the term restorative (from Inskipp and Proctor, 1988) rather than support, but, in the global north at least, there is broad similarity across disciplines in how the functions are understood. There is also shared perception of how the management or administrative function has assumed a dominant position within practitioners' supervision, reflecting the influence of managerialism; societal preoccupation with risk and a culture of inspection and audit (Adamson, 2011; Beddoe, 2010; Johnston, Noble, \& Gray, 2016; Noble \& Irwin, 2009). When attention is directed to the supervision of supervisors, this imbalance of functions appears yet more acute but without the same critical scrutiny of what it means when support and development are superseded by managerial priorities. In some work settings, supervision may be rebranded as a business meeting, communicating a clear message that administrative issues take precedence. This is at odds with formal policy documents which rarely indicate that professional supervision is limited to practitioners alone or that the purpose of supervision mutates at different levels of the hierarchy. While this article is focused primarily on managers' support needs, the tendency to prioritise staff training needs above their own (Patterson \& George, 2014; Ofsted, 2012) may, in part, arise because professional development is low on the agenda in their own supervision.

The role of support within supervision is never wholly straightforward with justified concerns about the risk of prioritising workers' interests over those of people using services. Cousins (2010) highlights the way supervisors can inadvertently collude with a treat me, don't beat me game, slipping into therapeutic mode and losing focus on the service user. Different strategies may be employed to hold the child or adult in mind but a definition of outcomes as "the impact of activity or support" on a person's life (Cook \& Miller, 2012, p. 8) can serve as useful anchor point in supervision. While evidence of such impact remains limited and often anecdotal (Carpenter, Webb, Bostock, \& Coomber, 2012), the reminder that supervision is striving to make a difference for the better in people's lives is important. This conscious intent has validity regardless of how far removed from direct practice supervision takes place. Hughes and Pengelly's (1997) model encompasses three dimensions of managing service delivery, facilitating practitioner's professional development and focusing on practitioner's work. Their approach translates effectively across to managerial roles, legitimising those elements which risk being overlooked: facilitating managers' professional development and focusing on managers' work. The supervision of staff is fundamental to their work and is a complex activity with far-reaching implications for the quality of practice (Ofsted, 2012). It is noteworthy, therefore, how limited the opportunities are for managers to reflect in depth on their supervisory practice; to examine the skills they are using and to identify process dynamics at work below the surface in supervision.

Various models of peer or group supervision offer space for such reflection (Golia \& McGovern, 2015; Patterson, 2017; Wallbank, 2013a) and Davys, Howard, Rankine, \& Thompson (2019) describe a process 
of thinking aloud used within a small learning community to deepen participants' supervisory skills and competence. Approaches such as these may complement and enhance line management supervision or, alternatively, may compensate for what is missing in formal structures. Debates about the merits of separating line management from clinical or reflective supervision (Bostock, 2015; Bradley \& Höjer, 2009; Children's Workforce Development Council, 2010; Wong \& Lee, 2015) are contextdependent but, whether the intent is to counter-balance a managerialist culture or address the needs of diverse professionals in an integrated setting, there are benefits and drawbacks to consider. Amongst these is the risk of splitting, or the organisation failing to provide effective containment for work that is, of necessity, emotion-laden and challenging, if support is de-coupled from management supervision.

The Ofsted report of 2012 identified "the importance of holistic and systemic support for staff" (p. 5) and noted that "effective support depended on the creation of organisational cultures that were characterised by high expectations, high support and high challenge" (p. 6). The report's focus was on direct practice with children and families but its emerging themes of a systemic approach; the importance of "senior managers modelling the behaviours required of effective supervisors" (p. 17), and the way in which a relationship-based culture was mirrored in work with parents, demonstrate that congruence across every level of an organisation is critical. Sound support and supervision for managers resources them in their vital role of supporting frontline staff. Sustaining good supervision demands that attention be paid to the support and development of supervisors as well as the functional tasks assigned to them.

\section{Containing the container}

The support or restorative function within supervision is bound up with the emotional impact of practice. Working in close proximity with painful human experience affects those involved. Too intense an involvement with powerful emotions can be debilitating but too great a distancing, or denial of the feelings evoked, renders practice unsafe (Dwyer, 2007; Horwath, 2016; Stanley \& Goddard, 2002). One of the purposes of supervision is to offer a space where emotions are valued and legitimised. A worker's affective response may at times distort their judgement, giving a false sense of certainty or introducing bias into their decision-making but can also alert them to concerns which might go unnoticed. There are risks in attaching too much or too little weight to emotional information and a supervisor's role is to help explore what is significant. While knowledge of a practitioner's caseload is helpful, so too is a degree of detachment which enables the supervisor to question certitude (Laming, 2009), to offer a different perspective and to observe details which may have become invisible to the worker.

Supervision, ideally, provides the kind of emotional containment which sustains people's capacity to carry out their work without doing damage to their health and wellbeing or blunting their responsiveness as a caring professional. In an early edition of Supervision in the Helping Professions, Hawkins and Shohet (1989) drew comparisons with coal miners' right to wash off the pit-grime in their working time rather than carry it back to their homes and families. And Zagler-Roberts (1994) warns that uncontained staff may lose the passion and commitment that drew them to work in a caring role. Rooted in psychodynamic theory, the concept of containment is based on the idea that a parent or caregiver contains the anxiety which threatens to overwhelm a hungry, tired or fearful infant by providing a consistent and reassuring response. Feelings which were unbearable become possible to endure and relief is provided. While supervision does not seek to infantilise or to rescue a practitioner, the ability to listen and contain feelings 
of vulnerability, loss, anger or frustration without being overwhelmed allows these to be processed. Through a collaborative working alliance, the supervisor and supervisee can find a way forward which does not deny the challenge faced but makes it more manageable.

In the context of residential care for older people, Jones and Wright (2008, p. 341) suggest that containing supervision "may be considered as not too rigid and not too fragile". The supervisor needs to actively feel the worker's emotions while still "retaining balance of mind." Writing about the supervision of fear, Smith (2000, p. 25) describes how a "combination of availability and attention .... may aid supervisees in finding a reassurance in and of themselves". He notes the value of a supervisor being prepared to think about a worker's experiences with them. It is not necessarily action that is helpful but a willingness to be there, to give time and to listen without criticism. Ruch's (2012) model of holistic containment shows how other structures within the workplace can complement supervision, supporting relationship-based approaches at management level and in direct practice. This helpfully points to a wider organisational responsibility; taking ownership of how its core activity, or primary task, impacts on staff and seeking to contain this effectively at the level of feeling, thinking and doing.

This brief overview of supervision's containing function makes evident a flawed logic if support for the emotional impact of the work is offered only to direct practitioners. While managers may be one or more steps removed from frontline practice, they are potentially holding the anxiety of a team of workers and in addition may be covering the caseload of absent staff or vacant posts. Toasland (2007) describes the pressure on first-line managers to be the "primary container" capable of holding the projections of others while neither colluding nor withdrawing. Holding a middle position between operational and strategic imperatives, they are subject to the anxieties of referrers and senior managers as well as practitioners and therefore need their own "positive containing supervision" in which to process rather than be driven by such pressures (Toasland, 2007, p. 202). Morrison's (2005) three-cycle model of the impact of anxiety on supervision demonstrates the importance of a systems perspective. Drawing on Vince and Martin's (1993) work, Morrison distinguishes between a collaborative organisational environment capable of holding uncertainty, risk and ambiguity and a compromised organisational environment which lacks containment or safety. The latter risks the kind of dysfunctional social defence systems (Menzies-Lyth, 1970) which impact at individual, team and organisational levels, undermining trust and diverting attention from the primary task while a collaborative organisational environment is characterised by its capacity, at every level of management, to stay clearly focused on people who use services.

Writing in a health context, Wallbank (2013b, p. 176) suggests that "restorative supervision provides a parallel process where the leader feels supported and understood and is able to provide that experience to their staff." This is an example where the restorative dimension of supervision has been identified as a distinct element to be addressed independently and not conflated with line management. The value of clinical supervision for nursing managers has been explored in earlier studies (Johns, 2003; Sirola-Karvinen \& Hyrkäs, 2008) but in relation to broader leadership capabilities rather than their capacity to respond to the emotional impact of practice. Action learning sets for supervisors (Patterson, 2017) offer another approach based on peer collaboration which enables managers to identify and explore issues affecting them personally as well as professionally. Across the helping professions and in the context of ever-increasing pressures, attending to the support needs of managers is important if they are not to become overwhelmed or 
their capacity for empathy blunted (Cousins, 2004). There is a need to contain the container and model a supervision culture which attends to feelings as well as tasks.

\section{Reflection and reflexivity in the supervisory role}

Reflective supervision is promoted and aspired to in many work settings but not always evident in practice (Wilkins et al., 2017). Aside from competing pressures on the time available, shifting into reflective mode and holding back from problemsolving challenges habitual ways of being. Arguably, if managers have little opportunity for reflection within their own working schedule, it is less likely that they will readily adopt a supervision style which is open and curious. The importance of reflective supervision is not in question but there is risk of another fracture between the espoused and the actual if it is valued in name alone.

Exploring the purpose of reflection in supervision and the constraints which impinge may be a useful starting place. This is not to imply there is an ideal approach but is a way of delving below the surface of what an individual supervisor is striving for. One intent may be to foster a practitioner's development and autonomy by refraining from offering advice; encouraging them to consider a situation in more depth, to reflect on alternative options and their implications. In this instance the reflective activity is undertaken primarily by the supervisee while the supervisor may, or may not, be open to changing their views on what is an appropriate course of action. Various adaptations of a reflective learning cycle (Davys \& Beddoe, 2010; Kolb, 1984) are used in supervision to structure a sensemaking process in which both supervisor and supervisee can participate. This opens up space between action and reaction where thoughtful attention is given to an issue before deciding how to move forward. A critical reflective approach may go further and focus more specifically on power relationships; positions of privilege and disadvantage, with the aim of challenging dominant ideologies and questioning the status quo. This critical gaze could be directed at structural inequalities affecting the lives of people who use services but equally might include aspects of organisational policy. In this instance, a supervisor may experience tension in the reflective process between their values and their management role.

A further possibility is reflection striving for greater depth of understanding rather than setting a course of action. This is particularly challenging in task-focused and accountability-driven cultures but has a valid place within supervision. Negative capability (Cornish, 2011; Grint, 2010) is the capacity to sit with un-knowing and it may be important for practitioners to "stay in uncertainty for longer" (Taylor \& White, 2006, p. 944). Although it can provoke discomfort or even hostility, there are situations where it is necessary to reflect on what is going on at an unconscious level.

Is this unknown because the worker is afraid to ask? Is this unknown because the worker is defending him, or herself..... Is this unknown because someone wants it to remain unknown? (Goddard \& Hunt, 2011, p. 425)

The capacity to tolerate uncertainty calls for trust in the process and knowledge of self. Grint (2010) argues that, in the face of complexity, the art of the leader is to ask better questions rather than collude with the desire for a simple answer. However, not every supervisor may feel confident to hold that space of open inquiry and not every supervisee will be receptive to a dialogic approach (Bohm, 1996; Schein, 2013).

Whatever kind of reflective supervision is practised, there is a need to pay attention to inner as well as outer process. Hawkins and Shohet's (2012) seven-eyed model represents the multi-layered awareness which can inform supervision. This extends 
beyond Schön's (1983) reflection-in-action and requires a supervisor to be alert and responsive to many simultaneous cues. Such high expectations can be paralysing, particularly for an inexperienced supervisor, and the greatest value of the model may be its reminder of the complexity of the supervisory process; raising awareness of how much is going on below the surface and how rich, but potentially confusing, the sources of insight are beyond what is spoken. In supervision-triad work within a post-qualifying module, participants role play scenarios and reflect on the interaction: what worked well and what could have been done differently. The perceptions of supervisor, supervisee and observer may diverge, which itself is informative, but of particular note is how much happens within these brief interactions. Focusing a lens on the detail of what goes on; what choices are made and how the supervisee is enabled or blocked in their exploration of an issue can be a fascinating revelation. It is also evident that, for many people, examining the process rather than the content of a session is an unfamiliar activity. There is good understanding of the part played by body language and active listening, but indepth analysis of subtle shifts in mood or the impact of particular words or gestures seems less within reach. It can feel like tangible resistance to exploring the dynamics at play and an inexorable pull towards discussing a more concrete problem.

Opportunities to practise skills; to experiment with new approaches and to get critical feedback are surprisingly rare given the significance of supervision. Not only do many supervisors take on the role with limited training or preparation (Cousins, 2004; Patterson, 2015), there are also restricted opportunities for continuing development apart from what is learnt on the job. If supervision is to address depth rather than surface (Howe, 1996) the reflective supervisory needs of managers deserve greater priority. The structure for achieving this, whether individual, peer, group or other approaches, is less critical than commitment to a culture of reflection which permeates the whole of an organisation leading to practice which is aligned with policy aspirations.

Froggett (2000) highlights the impact of mirroring within social work "whereby the dynamics of the relationship between worker and client are unconsciously replayed in the supervisory relationship where they can become available for subsequent reflection" (Mattinson, 1975, cited in Froggett, 2000, p. 30). A reverse mirroring process means that supervisor-supervisee interactions may, in turn, affect direct practice. A supervisor's own supervision can help them identify their vulnerabilities, triggers and blind spots so they can engage more effectively with complex process dynamics. Examples might range from working with a supervisee whose assertive stance undermines the supervisor's sense of personal authority triggering an overly deferential or domineering response to supporting a worker regain perspective on a practice situation which has evoked painful emotions. It includes being mindful of the defence mechanisms which function at individual and organisational levels; having a compassionate understanding of these protective responses but being alert to their impact on the core task and the people whom the organisation is supposed to serve. A systems awareness challenges us to recognise that, whatever is present in the group, the organisation, the wider system is also present in ourselves. It is valuable, therefore, that supervisors are familiar with the defensive responses stirred up by work which is anxiety-provoking and have strategies in place to recognise and engage with these.

\section{Conclusion}

The focus of this article is the supervision of supervisors, a topic under-explored in the literature and at risk of being undervalued in practice. Despite the significance of their supervisory role including impact on direct work with people using services, there is a curious disjuncture in the attention paid to 
training, supporting and developing firstline supervisors. The suggestion is not that managers' supervision should replicate what they provide to practitioners. While the article is structured around established themes from supervision theory, it seeks to explore what kind of support can enhance managers' supervisory practice with the intent of benefiting both frontline staff and the people they work with. Paying attention to the significant transition from practice into a management role is a first step and developmental models can help to chart the journey into new terrain. Supervisors who are committed to balancing the managerial with the professional can better resist the pressure of surveillance over reflection (Beddoe, 2010) if their own support and development needs are not side-lined by administrative priorities. Their capacity to offer holistic containment (Ruch, 2012) is enhanced when they have space to process the emotional dimensions of their work and when an active learning culture is fostered for managers and practitioners alike.

The metaphor of a golden thread is often chosen when organisations strive to align strategy, values and practice. Supervision offers a valuable strand within that thread when there is a congruent and consistent approach; when actions match words and when policy aspirations are mirrored in people's lived experience.

\section{References}

Adamson, C. (2011). Supervision is not politically innocent. Australian Social Work, 65, 185-196. doi:10.1080/03124 07X.2011.618544

Beddoe, L. (2010). Surveillance or reflection: Professional supervision in the "risk" society. British Journal of Social Work, 40(4), 1279-1296. doi:10.1093/bjsw/bcq018

Beddoe, L., \& Davys, A. (2016). Challenges in professional supervision. London, UK: Jessica Kingsley.

Bion, W. (1962). Learning from experience. London, UK: Heinemann.

Blanchard, K H., Fowler, S., \& Hawkins, L. (2006). Selfleadership and the one minute manager: Discover the magic of no excuses: Increasing effectiveness through situational self leadership. London, UK: HarperCollins.

Bohm, D. (1996). On dialogue. Abingdon, UK: Routledge.

Bostock, L. (Ed.). (2015). Interprofessional staff supervision in adult health and social care services (Vol. 1). Brighton, UK: Pavilion Publishing.
Bradley, G., \& Höjer, S. (2009). Supervision reviewed: Reflections on two different social work models in England and Sweden. European Journal of Social Work, 12(1), 71-85. doi:10.1080/13691450802220990

Carpenter, J., Webb, C., Bostock, I., \& Coomber, C. (2012). Effective supervision in social work and social care. Social Care Institute for Excellence Research Briefing 43. Retrieved from www.scie.org.uk

Carroll, M. (2009). Supervision: Critical reflection for transformational learning, Part 1. The Clinical Supervisor, 28, 210-220.

Children's Workforce Development Council. (2010). Inspiring practice: A guide to developing an integrated approach to supervision in Children's Trusts. Leeds, UK: Author.

Cook, A., \& Miller, E. (2012). Talking points: Personal outcomes approach. Edinburgh, Scotland: Joint Improvement Team.

Cornish, S. (2011). Negative capability and social work: Insights from Keats, Bion and business. Journal of Social Work Practice, 25(2), 135-148. doi:10.1080/02650533. 2011.554974

Coulshed, V., \& Mullender, A. (2006). Management in social work, (3rd ed.). Basingstoke, UK: Palgrave Macmillan.

Cousins, C. (2004). Becoming a social work supervisor: A significant role transition. Australian Social Work, 57(2), 175-185.

Cousins, C. (2010). "Treat me don't beat me" .... Exploring supervisory games and their effect on poor performance management. Practice, 22(5), 281-292. doi:10.1080/095 03153.2010.514044

Davys, A., \& Beddoe, L. (2010). Best practice in supervision: A guide for the helping professions. London, UK: Jessica Kingsley Publishers.

Davys, A., Howard, F., Rankine, M., \& Thompson, A. (2019). Supervision under the microscope: Critical conversations in a learning community. Practice. doi:10.1080/0950315 3.2018.1558196

Department of Health and Social Care. (2018). Postqualifying standards in social work practice in adult social care. Retrieved from https://www.gov.uk/ government/publications/adult-social-work-postqualifying-standards-knowledge-and-skills-statement

Dwyer, S. (2007). The emotional impact of social work practice. Journal of Social Work Practice, 21(1), 49-60. doi:10.1080/026505306

Froggett, L. (2000). Staff supervision and dependency culture: A case study. Journal of Social Work Practice, 14(1), 27-35. doi:10.1080/713683880

Goddard, C., \& Hunt, S. (2011). The complexities of caring for child protection workers: The contexts of practice and supervision. Journal of Social Work Practice, 25(4), 413-432. doi:10.1080/02650533.2011.626644

Golia, G. M., \& McGovern, A. R. (2015). If you save me, I'll save you: The power of peer supervision in clinical training and professional development. British Journal of Social Work, 45(2), 634-650. doi:10.1093/bjsw/bct138

Grint, K. (2010). Wicked problems and clumsy solutions: The role of leadership. In S. Brookes \& K. Grint (Eds.), The new public leadership challenge (pp.169-186). Basingstoke, UK: Palgrave Macmillan.

Harlow, L. (2016). The management of children and family social workers in England: Reflecting upon the meaning 
and provision of support. Journal of Social Work, 16(6), 674-687. doi:10.1177/1468017315607092

Hawkins, P., \& Shohet, R. (1989). Supervision in the helping professions (1st ed.). Buckingham, UK: Open University Press.

Hawkins, P., \& Shohet, R. (2006). Supervision in the helping professions (3rd ed.). Maidenhead, UK: Open University Press.

Hawkins, P., \& Shohet, R. (2012). Supervision in the helping professions. (4th ed.). Berkshire, UK: Open University Press.

Hawkins, P., \& Smith, N. (2006). Coaching, mentoring and organizational consultancy: Supervision and development. Maidenhead, UK: Open University Press.

Hess, A. K. (1986). Growth in supervision: Stages of supervisee and supervisor development. The Clinical Supervisor, 4(1-2), 51-67. doi:10.1300/J001v04n01_04

Holmes, D. (2018). Showing our workings out-an update on the PSDP so far. Research in Practice. Retrieved from https://www.rip.org.uk/news-and-views/blog/showingour-workings-out- $\%$ E2\%80\%93-an-update-on-the-psdpso-far/

Horwath, J. (2016). The toxic duo: The neglected practitione and a parent who fails to meet the needs of their child. British Journal of Social Work, 46(6), 1602-1616. doi:10.1093/bjsw/bcv086

Howe, D. (1996). Surface and depth in social work practice. In N. Parton (Ed.), Social theory, social change and social work: The state of welfare (pp. 77-97). London, UK: Routledge.

Hughes, L., \& Pengelly, P. (1997). Staff supervision in a turbulent environment: Managing process and task in front-line services. London, UK: Jessica Kingsley Publishers.

Inskipp, F., \& Proctor, B. (1988). Skills for supervising and being supervised. Twickenham, Middlesex: Cascade Publications.

Johns, C. (2003). Clinical supervision as a model for clinical leadership. Journal of Nursing Management, 11(1), 25-34.

Johnston, L. Noble, C., \& Gray, M. (2016). Critical supervision for the human Services: $A$ social model to promote learning and value-based practice. London, UK: Jessica Kingsley.

Jones, C., \& Wright, J. C. (2008). It's time it ended and yet I hesitate, I hesitate to end it: The emotional world of an old people's home. Journal of Social Work Practice, 22(3), 329-343. doi:10.1080/02650530802396668

Kadushin, A. (1976). Supervision in social work. New York. NY: Columbia University Press.

Kolb, D. (1984). The process of experiential learning. In D. Kolb (Ed.), Experience as the source of learning and development. London, UK: Prentice Hall.

Laming, Lord. (2009). The protection of children in England: A progress report. Norwich, UK: The Stationery Office.

Lees, A., Meyer, E., \& Rafferty, J. (2013). From Menzies Lyth to Munro: The problem of managerialism. British Journal of Social Work, 43(3), 542-558. doi:10.1093/bjsw/bcr183

Menzies-Lyth, I. (1988). Containing anxiety in institutions: Selected essays (Vol 1). London, UK: Free Association Books.
Mor Barak, M. E., Travis, D., \& Bess, G. (2004). Exploring managers' and administrators' retrospective perceptions of their MSW fieldwork experience: A national study. Administration in Social Work, 28(1), 21-44.

Morrison, T. (1993). Staff supervision in social care (1st ed.). Harlow, UK: Longman.

Morrison, T. (2005). Staff supervision in social care: Making a real difference for staff and service users (3rd ed.). Brighton, UK: Pavilion Publishing.

Noble, C., \& Irwin, J. (2009). Social work supervision: An exploration of the current challenges in a rapidly changing social, economic and political environment. Journal of Social Work, 9(3), 345-358. doi:10.1177/1468017309334848

Obholzer, A. (1994). Authority, power and leadership: Contributions from group relations training. In A Obholzer \& V. Zagler-Roberts (Eds.), The unconscious at work: Individual and organisational stress in the human services (pp. 39-47). London, UK: Routledge.

Ofsted. (2012). High expectations, high support, high challenge: Protecting children more effectively through better support for front line practice. Retrieved from https://www.gov.uk/government/uploads/system/uploads/ attachment_data/file/419130/High_expectations_high_ support_and_high_challenge.pdf

Patterson, F. (2015). Transition and metaphor: Crossing a bridge from direct practice to first line management in social services. British Journal of Social Work, 45(7), 2072-2088. doi:org.10.1093/bjsw/bcu034

Patterson, F. (2017). A good fit: The contribution of action learning to supervision practice. Social Work Education, 36(1), 48-61 doi.org/10.1080/02615479.2016.1246523

Patterson, F., \& George, C. (2014). Middle managers in Scotland's social services: Leadership learning needs [internal publication]. Dundee, Scotland: SSSC

Pithouse, A. (1987). Social work: The social organisation of an invisible trade. Aldershot, UK: Avebury.

Rankine, M., Beddoe, L., O'Brien, M., \& Fouché, C. (2018). What's your agenda? Reflective supervision in community-based child welfare services, European Journal of Social Work, 21(3), 428-440. doi:10.1080/136 91457.2017.1326376

Ruch, G. (2008). Developing "containing contexts" for the promotion of effective direct work: the challenge for organisations. In B. Luckock \& M. Lefevre (Eds.), Direct work: Social work with children and young people in care (pp. 295-305). London, UK: BAAF, Adoption \& Fostering.

Ruch, G. (2012). Where have all the feelings gone? Developing reflective and relationship- based management in child-care social work. British Journal of Social Work, 42(7), 1315-1332. doi:10.1093/bjsw/bcr134

Saltiel, D. (2017). Supervision: A contested space for learning and decision making, Qualitative Social Work, 16(4), 533-549. doi:10.1177/1473325016633445

Schön, D. A. (1983). The reflective practitioner. New York, NY: Basic Books

Schein, E. H. (2013). Humble inquiry. San Francisco, CA: Berrett-Koehler.

Sirola-Karvinen, P., \& Hyrkäs, K. (2008). Administrative clinical supervision as evaluated by the first-line managers in one health care organization district. Journal of Nursing Management, 16, 588-600. 
Smith, M. (2000). Supervision of fear in social work. A re-evaluation of reassurance. Journal of Social Work Practice, 14(1), 17-26. doi:10.1080/713683886

Stanley, J., \& Goddard, C. (2002). In the firing line: Violence and power in child protection work. Chichester, UK: Wiley.

Stoner, C. R., \& Stoner, J. S. (2013). Building leaders. Abingdon, UK: Routledge.

Strandgaard, F. (1981). NLP made visual. Copenhagen, Denmark: Connector.

Taylor, C., \& White, S. (2006). Knowledge and reasoning in social work: Educating for humane judgement. British Journal of Social Work, 36(6), 937-954. doi:0.1093/bjsw/ bch365

Toasland, J. (2007). Containing the container: An exploration of the containing role of management in a social work context. Journal of Social Work Practice, 21(2), 197-202. doi:10.1080/02650530701371903

Tolleson Knee, R., \& Folsom, J. (2012). Bridging the crevasse between direct practice social work and management by increasing the transferability of core skills. Administration in Social Work, 36, 390-408.

Vince, R. \& Martin, L. (1993) Inside action learning: the politics and the psychology of the action learning model. Management Education and Development 24(3), 205- 215.

Wallbank, S. (2010). Using restorative resilience supervision to support professional to thrive. In L. Bostock (Ed.), Interprofessional staff supervision in adult health and social care services (pp. 57-62). Brighton, UK: Pavilion Publishing.

Wallbank, S. (2013a). Maintaining professional resilience through group restorative supervision. Community Practitioner, 86(8), 26-28.

Wallbank, S. (2013b). Reflecting on leadership in health visiting and the restorative model of supervision. Journal of Health Visiting, 1(3), 173-176. doi:10.12968/ johv.2013.1.3.97598

Ward, J. (2012). "1 once knew a team where all the workers called the manager 'mother"': Some reflections on supervision within an integrated leadership and management programme. Social Work and Social Sciences Review, 16(3), 65-80. doi:10.1921/40031603

Whittaker, A. (2011). Social defences and organisational culture in a local authority child protection setting: Challenges for the Munro Review? Journal of Social Work Practice, 25(4), 481-495. doi:10.1080/02650533. 2011.626654

Wilkins, D., Forrester, D., \& Grant, L. (2017). What happens in child and family social work supervision? Child and Family Social Work, 22, 942-951. doi:10.1111/cfs.12314

Wong, Y. J. P., \& Lee, Y. A. E. (2015). Dual roles of social work supervisors: Strain and strengths as managers and clinical supervisors. China Journal of Social Work, 8(2), 164-181. doi:10.1080/17525098.2015.1039168

Wonnacott, J. (2012). Mastering social work supervision. London, UK: Jessica Kingsley Publishers.

Zagler-Roberts, V. (1994). The organisation of work: Contributions from open systems theory. In A. Obholzer \& V. Zagler-Roberts (Eds.), The unconscious at work: Individual and organisational stress in the human services (pp. 28-38). London, UK: Routledge. 